\title{
Coefficient of Consolidation and Volume Change for 3-D Consolidation
}

\author{
Elsayed A. El-Kasaby, Elnos A. Eissa, Mohammed F. Abd-Elmagied, and Ahmed A. Abo-Shark
}

\begin{abstract}
The settlement is the most serious problem of fine soil. This settlement is caused by a phenomenon called soil consolidation. Most previous studies were concerned with studying one (1-D) and two-dimensional (2-D) consolidation. That in some cases does not give a simulation of reality representation. It was necessary to study the three-dimensional (3-D) consolidation to simulate what happens to the fine soil in nature. Therefore, the consolidation behavior of four fine soils was studied in this paper. The studied soil samples were collected at the foundation levels of four different sites in ElQalubia governorate, Egypt. A series of laboratory consolidation tests were carried out as one, two and three dimensional consolidation by using manufactured Oedometer apparatus. So, the effect of consolidation conditions (1-D, 2-D and 3-D) on consolidation coefficient $\left(C_{v}\right)$ and volume change coefficient $\left(m_{v}\right)$ was investigated. Also, an empirical equation was correlated the relationship between $C_{v}$ and $m_{v}$.
\end{abstract}

Index Terms-Consolidation, One Dimensional, Two Dimensional, Three Dimensional, Coefficient of Consolidation, Coefficient of Volume Change, Settlement,

\section{INTRODUCTION}

The consolidation process of soil mass is attributed to the increase of effective stresses on the fully saturated soil. So, the excess pore water pressure and the soil mass volume are reduced. Accordingly, the soil particles are forced together and rearranged, while, the water is allowed to drain out of the voids. Unquestionably, soil engineering properties, excess pore water $(\mathrm{u})$ and applied stresses $(\sigma)$ are the main factors affecting consolidation processes of underlying soil [1][2][3][4].A simple mechanism of the consolidation phenomenon was firstly proposed by assuming that particles constituting the soil are more or less bound together. The applied load on this system will produce a gradual settlement depending on the rate of water drained out the voids [5][6][7]. Many researchers were interested to predict the soil compressibility and soil consolidation behavior. The assumptions os basic properties of the consolidation are given in many references, [1][7][8][9].

Terzaghi's theory is limited to the one-dimensional field acting along the vertical direction only. Moreover, the onedimensional (1-D) consolidation theory constitutes the basis of soil mechanics, [10] [11]. The theory has never been fully applied as Taylor's approximate solution which is the convenient solution, [6]. So, the existence of the exact solution to Terzaghi's equation emerged from researches regarding the description of geotechnical phenomena through direct or inverse hyperbolic laws. This limitation is

Published on May 26, 2019

Authors are with the Civil Engineering Department, Benha Faculty of Engineering, Benha University, Cairo, Egypt. overcome through the study of the dependence of hydraulic and mechanical soil behavior on the effect of anisotropy, typically affecting sedimentary basins because of internal structures depending on the accumulation and deformation patterns in spatial and non-linear oedometer conditions, [13] [14]. For more indication, the geological evaluation of the basins leads to a structure that may more appropriately be described mathematically if it is treated as a transversely isotropic medium. Therefore, it can be provided with a plane of horizontal isotropy and an axis of vertical symmetry.

The coefficient of permeability at horizontal side is greater than that at the vertical, [2] [3] [4]. So, the consolidation must necessarily be dependent on this condition which may be extended to the three-dimensional case and is more consistent with actual hydraulic and mechanical behavior of soils. Accordingly, equations prove many points and describe the physical processes by means of second partial derivatives, [12] [15]. No one has studied the relationship between consolidation and volume change coefficients. So, the aim of this paper is to correlate between the two parameters at each condition of consolidation.

In this research, the experimental laboratory of consolidation tests were performed on fine soil samples using manufactured Oedometer apparatus. The obtained results were used to predict the effect of consolidation conditions (1-D, 2-D and 3-D) on consolidation and volume change coefficients. Also, relationships between these two parameters were investigated.

\section{EXPERIMENTAL APPLICATION}

For experimental applications, a series of consolidation tests were carried out as one-dimensional (1-D), twodimensional (2-D) and three-dimensional (3-D). These tests were performed using manufactured oedometer apparatus.

\section{A. The studied soils}

The studied soils S1, S2, S3 and S4 were collected from different sites at $2.75,6,8$ and $11 \mathrm{~m}$ from ground surface respectively. They were obtained from undisturbed samples which, extracted from soil borings. Table I contains the engineering properties of studied soils.

TABLE I: PROPERTIES OF THE STUDIED SOILS

\begin{tabular}{ccccc}
\hline \hline Soil No. & S1 & S2 & S3 & S4 \\
\hline Natural water content (\%) & 29.5 & 35 & 36 & 39 \\
Natural density (gm/cm3) & 1.90 & 1.88 & 1.96 & 2.02 \\
Specific gravity & 2.73 & 2.69 & 2.75 & 2.76 \\
Liquid limit (\%) & 71 & 63 & 74 & 81 \\
Plastic limit (\%) & 30 & 25 & 26 & 31 \\
Shrinkage limit (\%) & 17 & 18 & 16 & 15 \\
Plasticity index (\%) & 41 & 38 & 48 & 50 \\
Soil Classification (unified) & $\mathrm{CH}$ & $\mathrm{CH}$ & $\mathrm{CH}$ & $\mathrm{CH}$ \\
\hline \hline
\end{tabular}




\section{B. Manufactured consolidation apparatus and testing}

The ring of oedometer was manufactured from stainless steel of $50 \mathrm{~mm}$ height and $50 \mathrm{~mm}$ diameter. The undisturbed natural soil sample was placed inside this ring, so, the dimensions of the tested samples are $50 \mathrm{~mm}$ high and 50 mm diameter, Where:

a- At one dimensional consolidation (1-D)

The bottom side of the ring was completely closed using stainless steel base with rubber ring, then the porous stone with $5 \mathrm{~mm}$ thickness was placed above the tested samples, Fig.1-a.

b- At two dimensional consolidation (2-D)

The two porous stone with $5 \mathrm{~mm}$ thickness were placed on both top and bottom sides of the tested samples, Fig. 1-b.

c- At three dimensional consolidation (3-D) The cylindrical tube was manufactured from porous stone of $50 \mathrm{~mm}$ height, $50 \mathrm{~mm}$ internal diameter and $7 \mathrm{~mm}$ thickness. The undisturbed natural soil sample was placed inside porous tube. Then the porous stone with $5 \mathrm{~mm}$ thickness was placed on both top and bottom sides of the tested sample Fig. 1-c.

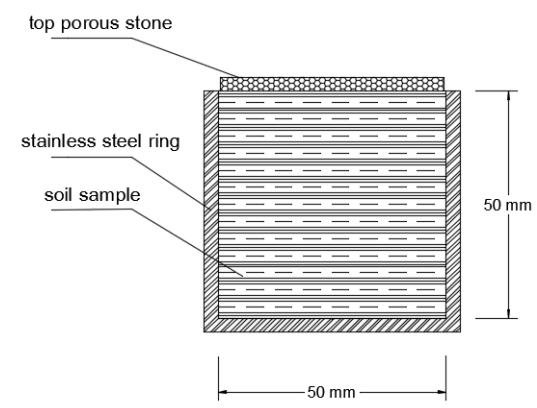

(a) One dimensional

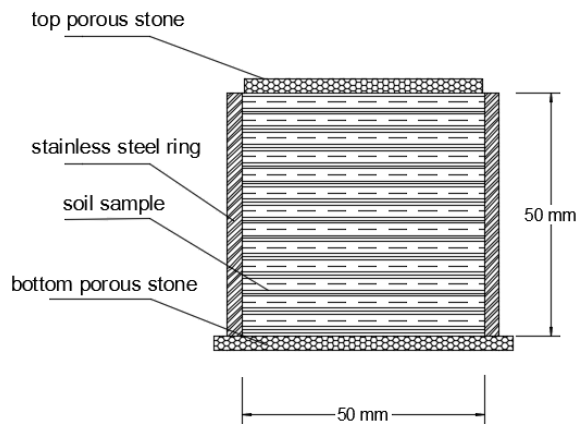

(b) Two dimensional

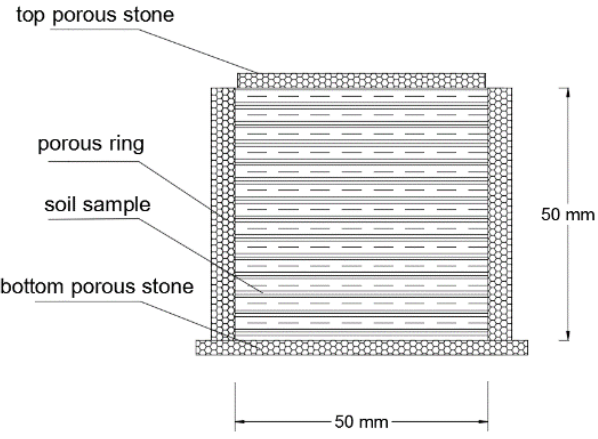

(c) Three dimensional

Fig. 1. Soil samples at each consolidation test condition

The loading bad was placed at the top of porous stone and the whole assembly was mounted on the loading frame.
Where, the applied load should be axially and centered with soil sample. Then, the dial gauge, with accuracy 0.01 $\mathrm{mm}$ /division, was arranged in apposition to record the behavior of soil samples in swelling and compressibility. The readings of dial gauge were recorded at various time intervals as: - 0.5, 1, 2, 4, 8, 15, 30 minutes, 1, 2, 4, 8 hours, $1,2,3,4 \ldots 7$ days till the readings completely constant. Three odometers apparatuses were used for laboratory consolidation tests as shown in Fig.2.

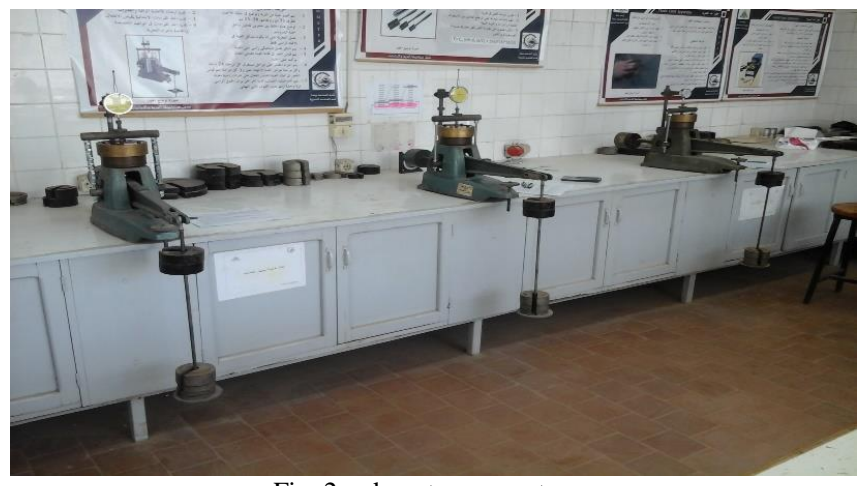

Fig. 2. odometer apparatuses

\section{RESULTS AND ANALYSIS}

Volume change coefficient $\left(\mathrm{m}_{\mathrm{v}}\right)$ and consolidation coefficient $\left(\mathrm{C}_{\mathrm{v}}\right)$ were determined according to consolidation test data of the studied soil samples. These coefficients $m_{v}$ and $\mathrm{C}_{\mathrm{v}}$ were determined using general manner of consolidation theory. So, the relationship between coefficient of volume change $\left(\mathrm{m}_{\mathrm{v}}\right)$ with applied stress increments $(\Delta \sigma)$ are shown in Figs.3, 4, 5 and 6 for the studied soil samples $\mathrm{S} 1, \mathrm{~S} 2, \mathrm{~S} 3$ and S4 respectively. While, Figs. 3, show the relationship between consolidation coefficient $\left(\mathrm{C}_{\mathrm{v}}\right)$ with each applied stress $(\sigma)$ for the studied soil samples S1, S2, S3 and S4 respectively.

\section{A. Coefficient of volume change $\left(m_{v}\right)$}

For each of consolidation conditions (1-D, 2-D and 3-D) the applied stress $(\sigma)$, the initial $\left(e_{o}\right)$ and final $\left(e_{f}\right)$ voids ratio of consolidated soil sample can be estimated. Then, the decrease values of voids ratio $(\Delta e)$ at each stress increment $(\Delta \sigma)$ are calculated. The stress increments $(\Delta \sigma)$ are 0.254 , $0.509,1.018,2.037$ and $4.074 \mathrm{~kg} / \mathrm{cm}^{2}$. According to the obtained results as shown in Figs. 3,4,5 and 6 , it is evident that:

1- Generally, the values of $m_{v}$ decrease gradually with the increase of applied stress. The maximum values of $m_{v}$ are at the applied stress increment $(\Delta \sigma) 0.254$ $\mathrm{kg} / \mathrm{cm}^{2}$ and the minimum values at $(\Delta \sigma) 4.074$ $\mathrm{kg} / \mathrm{cm}^{2}$.

- For S1 the $m_{v}$ value at $\Delta \sigma=4.074 \mathrm{~kg} / \mathrm{cm}^{2}$ decreases by about $23.60 \%$ less than that for $\Delta \sigma=0.254$ $\mathrm{kg} / \mathrm{cm}^{2}$.

- For S2 the $m_{v}$ value at $\Delta \sigma=4.074 \mathrm{~kg} / \mathrm{cm}^{2}$ decreases by about $30.13 \%$ less than that for $\Delta \sigma=0.254$ $\mathrm{kg} / \mathrm{cm}^{2}$.

- $\quad$ For S3 the $m_{v}$ value at $\Delta \sigma=4.074 \mathrm{~kg} / \mathrm{cm}^{2}$ decreases by about $37 \%$ less than that for $\Delta \sigma=0.254 \mathrm{~kg} / \mathrm{cm}^{2}$. 
- $\quad$ For S4 the $m_{v}$ value at $\Delta \sigma=4.074 \mathrm{~kg} / \mathrm{cm}^{2}$ decreases by about $30.5 \%$ less than that for $\Delta \sigma=0.254$ $\mathrm{kg} / \mathrm{cm}^{2}$.

2- The highest average values of $m_{v}$ are investigated at three dimensional consolidation (3-D) for each studied soil samples.

- $\quad$ For S1 the values of $m_{v}$ for 3-D are increased than that for 1-D and 2-D by about $8.4 \%$ and $4.8 \%$ respectively under each applied stress increment.

- For S2 the average values of $m_{v}$ for 3-D are increased than that for 1-D and 2-D by about $10.51 \%$ and $4.4 \%$ respectively under each applied stress increment.

- $\quad$ For S3 the average values of mv for 3-D are increased than that for 1-D and 2-D by about $15.27 \%$ and $7.68 \%$ respectively.

- For S4 the average values of $\mathrm{m}_{\mathrm{v}}$ for 3-D are increased than that for 1-D and 2-D for S4 by about $11.45 \%$ and $6.52 \%$ respectively.

3- The values of $m_{v}$ are related to the change of voids ratio $(\Delta e)$ and the complete compressibility of soil. Where, 1-D and 2-D need long decay time to reach complete consolidation $(\mathrm{U}=100 \%)$.
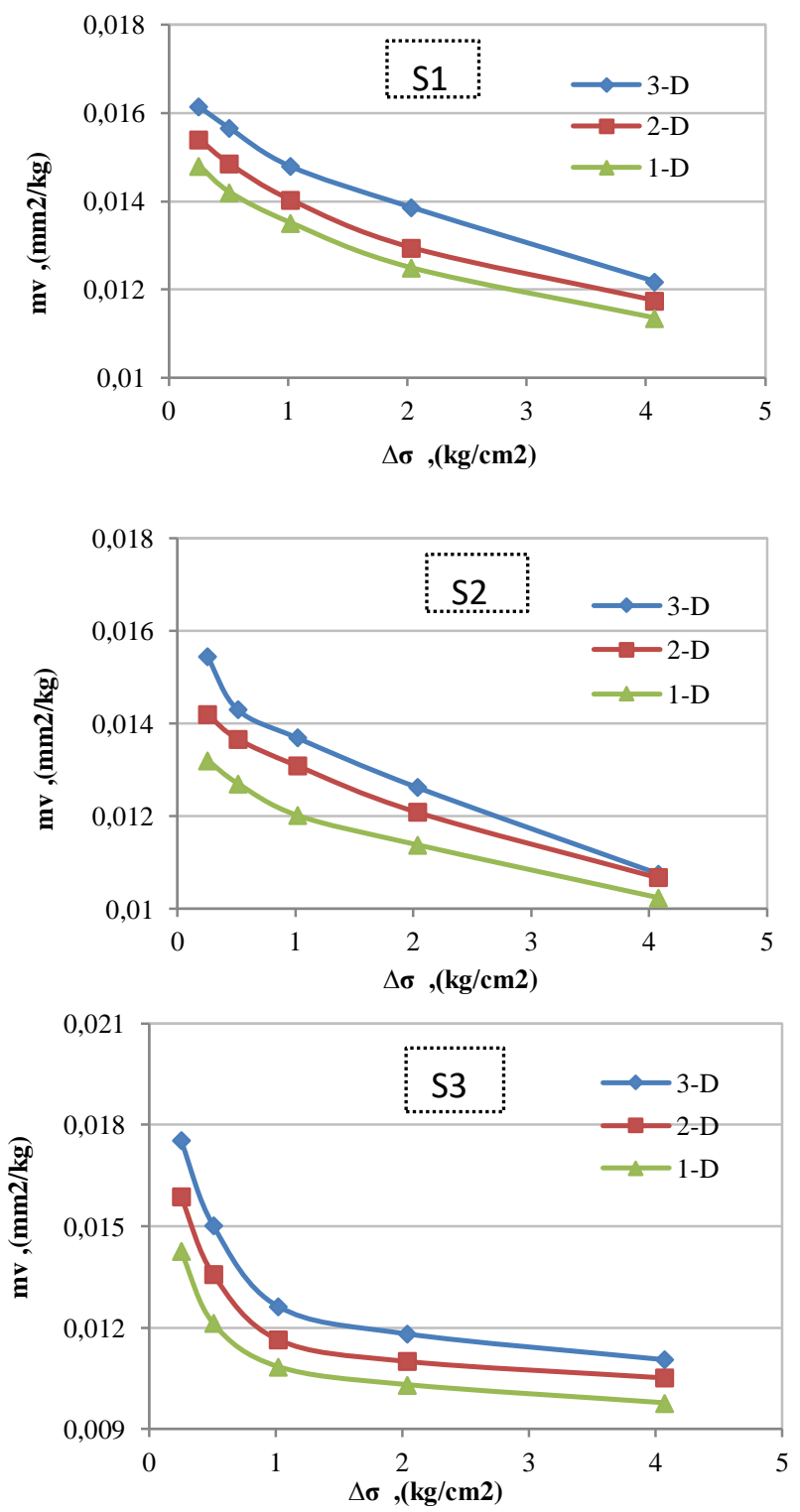

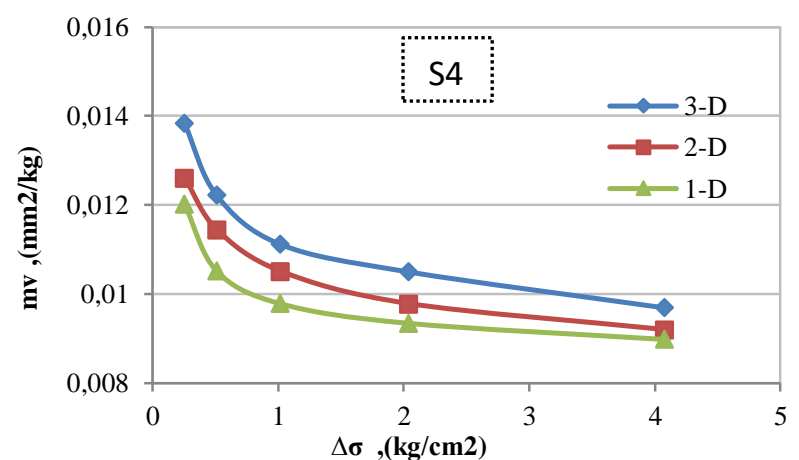

Fig. 3. Volume change coefficients $\left(\mathrm{m}_{\mathrm{v}}\right)$ at variant consolidation conditions

\section{B. Coefficient of consolidation $\left(C_{v}\right)$}

Consolidation coefficient $\left(\mathrm{C}_{\mathrm{v}}\right)$ can be calculated by the average of logarithm of elapsed time and root of elapsed time using the general manner. Fig. 4, indicates the consolidation coefficients $\left(\mathrm{C}_{\mathrm{v}}\right)$ at variant consolidation conditions for the studied samples S1 to S4 respectively. Where, the stress $(\sigma)$ are $0.5092,1.0185,2.0371 .4 .0743$ and $8.1487 \mathrm{~kg} / \mathrm{cm}^{2}$. Due to $\mathrm{C}_{\mathrm{v}}$ values, it is clear that:

1- In general, the values of $C_{v}$ decrease gradually with the increase of applied pressure. The maximum values of $C_{v}$ are at the applied stress $(\sigma) 0.509 \mathrm{~kg} / \mathrm{cm}^{2}$ and the low values at $(\sigma) 8.148 \mathrm{~kg} / \mathrm{cm}^{2}$.

- For $\mathrm{S} 1$, the value of $C_{v}$ at applied stress 8.148 $\mathrm{kg} / \mathrm{cm}^{2}$ decreases by about $52.6 \%$ less than that for applied stress $0.509 \mathrm{~kg} / \mathrm{cm}^{2}$ at 3-D consolidation.

- For $\mathrm{S} 2$, the value of $C_{v}$ at applied stress 8.148 $\mathrm{kg} / \mathrm{cm}^{2}$ decreases by about $46 \%$ less than that for applied stress $0.509 \mathrm{~kg} / \mathrm{cm}^{2}$ at the same condition of consolidation.

- For S3, the value of $C_{v}$ at applied stress 8.148 $\mathrm{kg} / \mathrm{cm}^{2}$ decreases by about $74 \%$ less than that for applied stress $0.509 \mathrm{~kg} / \mathrm{cm}^{2}$.

- For S4, the value of $C_{v}$ at applied stress 8.148 $\mathrm{kg} / \mathrm{cm}^{2}$ decreases by about $55.22 \%$ less than that for applied stress $0.509 \mathrm{~kg} / \mathrm{cm}^{2}$.

2- The highest average values of $\mathrm{C}_{\mathrm{v}}$ are investigated at three dimensional consolidation (3-D) for each studied soil samples.

- For $\mathrm{S} 1$, the average values of $C_{v}$ for 3-D are increased than that for 1-D and 2-D by about $36.8 \%$ and $24.6 \%$ respectively under applied stress.

- For $\mathrm{S} 2$, the average values of $C_{v}$ for 3-D are increased than that for 1-D and 2-D by about $24 \%$ and $17.2 \%$.

- $\quad$ For S3, the average values of $C_{v}$ for 3-D are increased than that for 1-D and 2-D about 37.24\% and $23.48 \%$.

- For S4, the average values of $C_{v}$ for 3-D are increased than that for 1-D and 2-D by about $33.26 \%$ and $23.315 \%$ respectively.

3- The elapsed consolidation time plays the main role for consolidation coefficient $\left(C_{\mathrm{v}}\right)$ value.

As mentioned in item 2.1, the studied soils are classified as $\mathrm{CH}$. Then the effect of the depth of soil sample location on the consolidation behavior is very slightly or negligible. 


\section{Correlation between coefficient of consolidation $\left(C_{v}\right)$} with coefficient of volume change $\left(m_{v}\right)$

Unquestionably, the volume change coefficient $\left(\mathrm{m}_{\mathrm{v}}\right)$ and consolidation coefficient $\left(\mathrm{C}_{\mathrm{v}}\right)$ plays a significant effect on consolidation process. In general, volume change $\left(\mathrm{m}_{\mathrm{v}}\right)$ controls the excess pore water pressure within the soil and the duration of consolidation, similarly consolidation coefficient $\left(\mathrm{C}_{\mathrm{v}}\right)$ express the duration of consolidation process. Thus, it was important to correlate these two parameters $\mathrm{m}_{\mathrm{v}}$ and $\mathrm{C}_{\mathrm{v}}$ at each condition of consolidation.
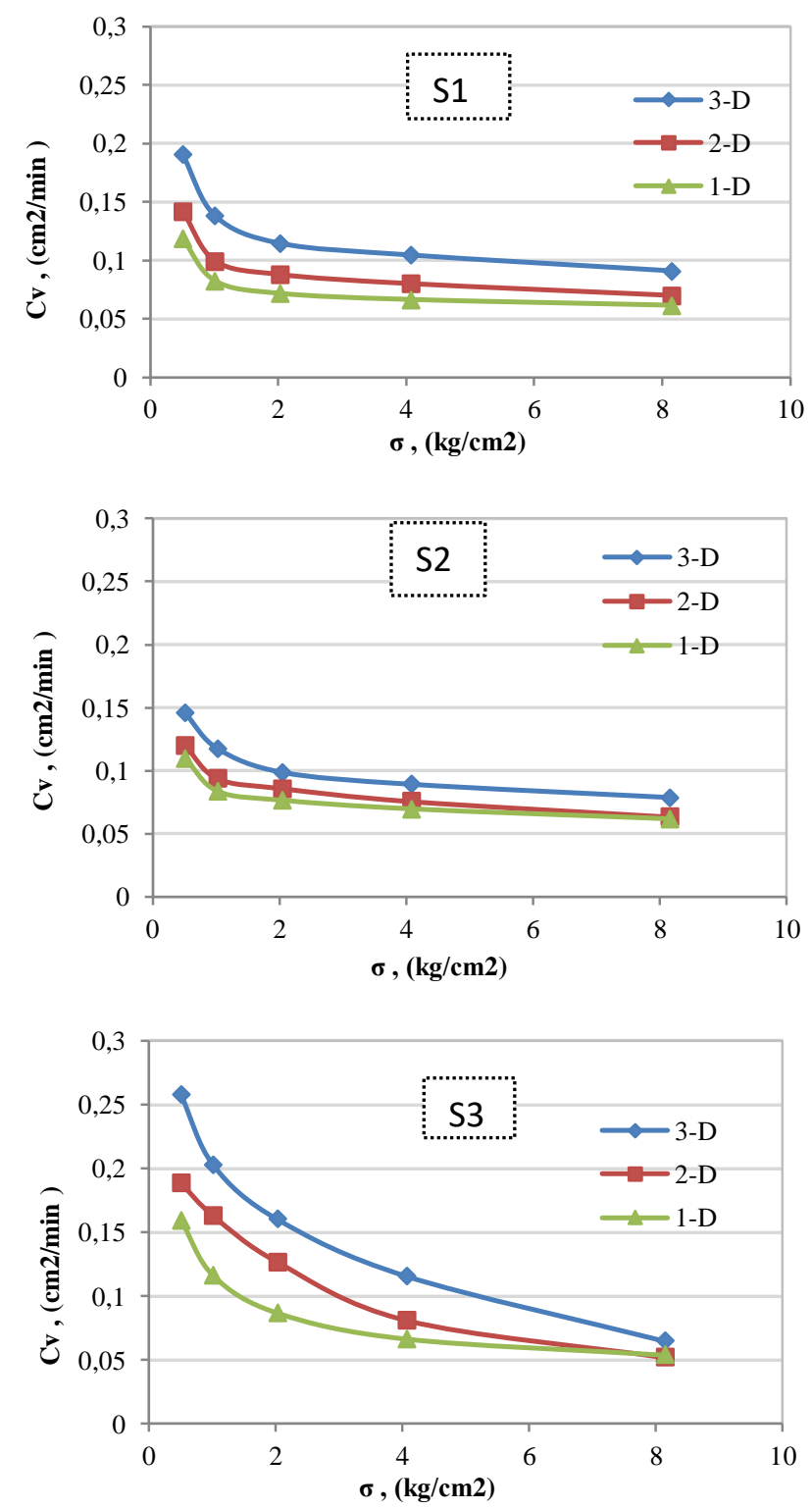

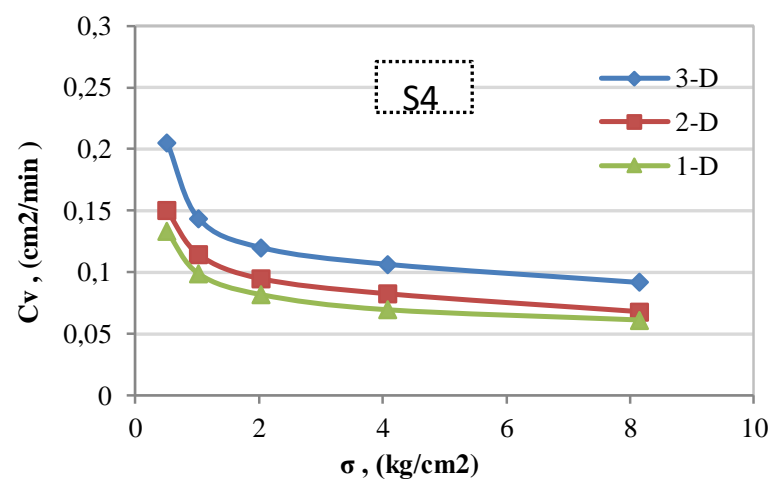

Fig. 4. Consolidation coefficients $\left(\mathrm{C}_{\mathrm{v}}\right)$ at variant consolidation condition.

The determined results of volume change coefficient $\left(\mathrm{m}_{\mathrm{v}}\right)$ and consolidation coefficient $\left(\mathrm{C}_{\mathrm{v}}\right)$ at one, two and three dimensional consolidation (1-D, 2-D and 3-D) are summarized in Table. 2. Additionally, by using data-fit software to correlated the relationship between consolidation coefficient $\left(\mathrm{C}_{\mathrm{v}}\right)$ with volume change coefficient $\left(\mathrm{m}_{\mathrm{v}}\right)$ for the studied soils $\mathrm{S} 1$ to $\mathrm{S} 4$ respectively, Fig. 3. Therefore, an empirical formula can deduce as:

$$
\mathrm{C}_{\mathrm{v}}=\mathrm{A}^{*} \mathrm{~m}_{\mathrm{v}}+\mathrm{B}
$$

Where, $\mathrm{C}_{\mathrm{v}}$ represent the consolidation coefficient $\left(\mathrm{cm}^{2} / \mathrm{min}\right), \mathrm{m}_{\mathrm{v}}$ represent volume change coefficient $\left(\mathrm{cm}^{2} / \mathrm{kg}\right)$. $\mathrm{A}$ and $\mathrm{B}$ are constants depending upon coefficient of consolidation of the tested soil sample. A and B variations are recorded. According to the values of $\mathrm{A}$ and $\mathrm{B}$ as a results of fitting the relationship between coefficient of consolidations $\left(\mathrm{C}_{\mathrm{v}}\right)$ and coefficient of volume change $\left(\mathrm{m}_{\mathrm{v}}\right)$ curves, it can be noted that:

1- At one dimensional consolidation (1-D): (a) The values of constant $A$ is ranged between 26.6 and 6.85 with average value about 16.7, (b) The values of constant $\mathrm{B}$ is ranged between 0.16 and 0.017 with average value 0.103 .

2- At two dimensional consolidation (2-D): (a) The values of constant $A$ is ranged between 34.6 and 9.1 with average value 18.48 , (b) The values of constant $\mathrm{B}$ is ranged between 0.3 and 0.038 with average value 0.124 .

3- At three dimensional consolidation (3-D): (a) The values of constant $\mathrm{A}$ is ranged between 32.5 and 9.9 with average value 18.91. (b) The values of constant $\mathrm{B}$ is ranged 0.27 between 0.03 with average value 0.136 .

Generally, the average value of constant A for the consolidation results at each condition of consolidation is 18.03, while the average value of constant $B$ for the consolidation results at each condition of consolidation is 0.121. So, the empirical formula can be written as:

$$
\mathrm{C}_{\mathrm{v}}=18.03 \mathrm{~m}_{\mathrm{v}}+0.121
$$


TABLE. II: $\mathrm{C}_{\mathrm{V}}$ AND M $\mathrm{M}_{\mathrm{V}}$ VALUES FOR THE STUDIED SOIL SAMPLES AT EACH CONDITION OF CONSOLIDATION

\begin{tabular}{|c|c|c|c|c|c|c|c|c|c|c|c|c|c|}
\hline \multirow{2}{*}{\multicolumn{2}{|c|}{$\begin{array}{c}\begin{array}{c}\text { Consolidation condition } \\
\text { stress }\end{array}(\mathrm{Kg} / \mathrm{cm} 2) \\
\end{array}$}} & \multicolumn{4}{|c|}{ 1-D } & \multicolumn{4}{|c|}{ 2-D } & \multicolumn{4}{|c|}{ 3-D } \\
\hline & & 1 & 2 & 4 & 8 & 1 & 2 & 4 & 8 & 1 & 2 & 4 & 8 \\
\hline \multirow{2}{*}{ S1 } & $\mathbf{m}_{\mathbf{v}} *\left(\mathbf{1 0}^{-3}\right)\left(\mathrm{cm}^{2} / \mathrm{kg}\right)$ & 0.142 & 0.135 & 0.125 & 0.113 & 0.148 & 0.140 & 0.129 & 0.117 & 0.157 & 0.148 & 0.139 & 0.122 \\
\hline & $(\mathrm{cm} 2 / \mathrm{min})$ & 0.082 & 0.072 & 0.066 & 0.062 & 0.099 & 0.088 & 0.080 & 0.070 & 0.138 & 0.115 & 0.105 & 0.091 \\
\hline $\mathbf{S 2}$ & $\mathbf{c}_{\mathbf{v}} \quad(\mathrm{cm} 2 / \mathrm{min})$ & 0.083 & 0.076 & 0.069 & 0.062 & 0.094 & 0.086 & 0.076 & 0.063 & 0.118 & 0.099 & 0.089 & 0.079 \\
\hline \multirow{2}{*}{ S3 } & $\mathbf{m}_{\mathbf{v}} *\left(\mathbf{1 0}^{-\mathbf{3}}\right)\left(\mathrm{cm}^{2} / \mathrm{kg}\right)$ & 0.121 & 0.108 & 0.103 & 0.098 & 0.136 & 0.117 & 0.110 & 0.105 & 0.150 & 0.126 & 0.118 & 0.111 \\
\hline & $(\mathrm{cm} 2 / \min )$ & 0.116 & 0.087 & 0.067 & 0.054 & 0.163 & 0.127 & 0.081 & 0.052 & 0.203 & 0.160 & 0.116 & 0.065 \\
\hline
\end{tabular}
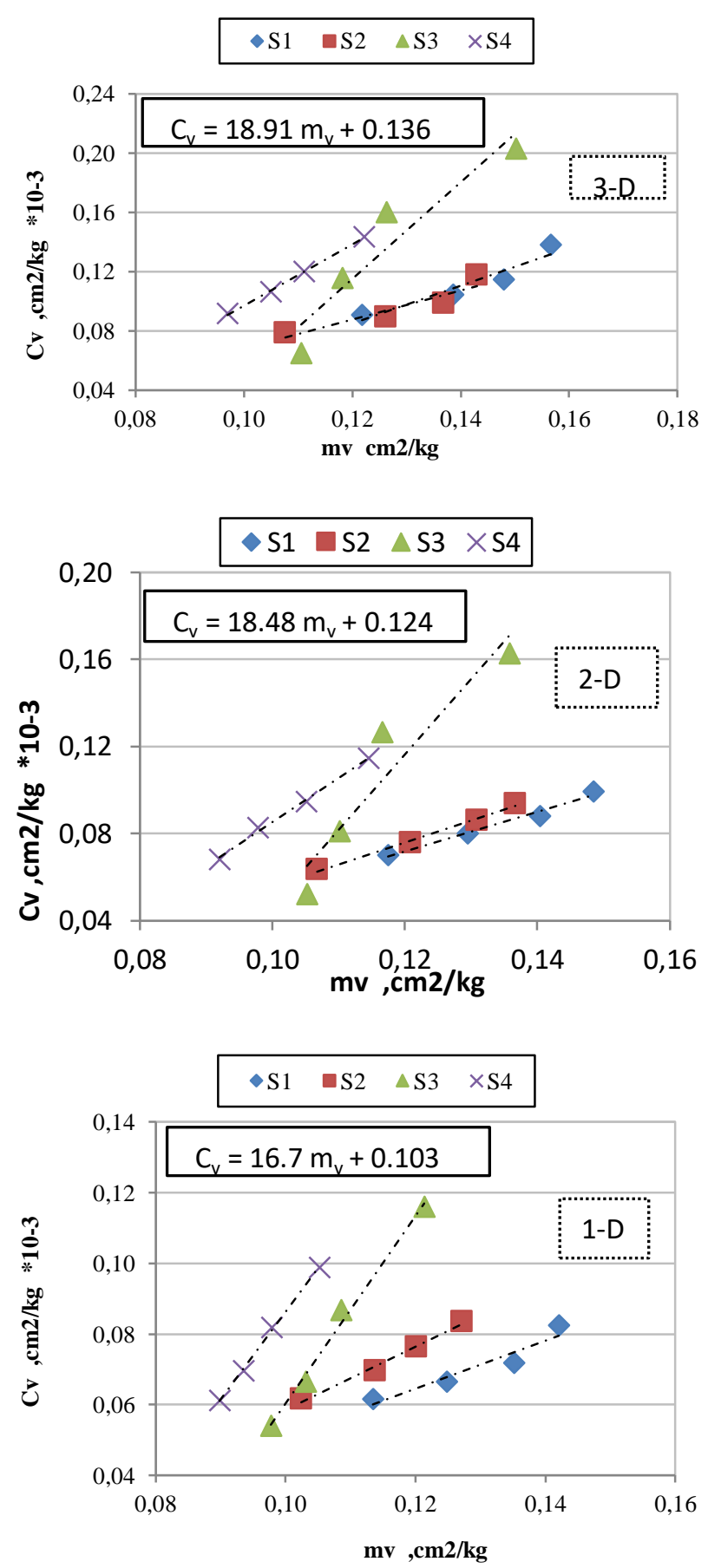

Fig. 5. Correlation of $\mathrm{C}_{\mathrm{v}}$ with $\mathrm{m}_{\mathrm{v}}$ values at each condition of consolidation for the studied soil samples.

\section{CONCLUSION}

The following conclusions can be drawn:

1. The values of volume change coefficient $\left(m_{v}\right)$ at 3-D decrease gradually with the increase of applied pressure. $m_{v}$ value at highest stress increments decreases by about $30.3 \%$ less than that for lower stress increments.

2. The average values of $m_{v}$ for 3-D consolidation are increased than that for 1-D consolidation and 2-D consolidation by about $11.40 \%$ and $5.85 \%$ respectively under each applied stress increment.

3. The application of consolidation test results shows a good correspondence with the decay times of the consolidation phenomenon. 3-D consolidation condition need less time to reach complete consolidation $(U=100 \%)$ than that for 1-D consolidation and 2-D consolidation.

4. The values of $C_{v}$ at 3-D consolidation decrease gradually with the increase of applied pressure. The values of $C_{v}$ at highest applied stress $(\sigma)$ decreases by about $56.95 \%$ less than that for lower applied stress.

5. The average values of $C_{v}$ for 3-D consolidation are increased than that for 1-D consolidation and 2-D consolidation by about $32.8 \%$ and $22.15 \%$ respectively under each applied stress.

6. An empirical formula was predicted as the relationship between volume change coefficient and consolidation coefficient.

\section{REFERENCES}

[1] M.A. Biot, Consolidation Settlement Under A Rectangular Load Distribution, Journal of Applied Physics, Vol. 12, No. 5, pp. 426-435, 1941.

[2] R.L. Handy, and M.G. Spangler, Geotechnical Engineering, Soil and Foundation Principles and Practice, McGraw Hill, 6th Edition, New York, USA, 2014.

[3] J.E. Bowles, Engineering Properties of Soils and Their Measurement, McGraw-Hill, New York, USA, 1986.

[4] H.A. Alnos, Influence of Contaminated Soil on Consolidation Parameters, Journal of Environmental Science for Sustainable Society (JESSS), Japan, Vol. 8, pp. 15-28, 2011.

[5] D.C. Helm, Three-Dimensional Theory in Terms of the Velocity of Solids, Geotechnique, Vol. 37, No. 3, pp. 369-392, 1987.

[6] D.W. Taylor, Fundamental of Soil Mechanics, John Wiley \& Sons, New York, USA, 1984.

[7] M.R. Karim, F. Oka, K. Krabbenhoft, S. Leroueil, and S. Kimoto, Simulation of Long-term Consolidation Behavior of Soft Sensitive Clay Using an Elasto-viscoplastic Constitutive Model, International Journal for Numerical and Analytical Methods for Geo-mechanics, Vol. 37, No. 16, pp. 2801-2824, 2013.

[8] T.W. Lambe, and R.V. Whitman, Soil Mechanics, John Wiley \& Sons, New York, USA, 1969.

[9] Y.K. Chcung, P.K.K. Lee, and K.H. Xie, Some Remarks on Two and Three Dimensional Consolidation Analysis of Sand-Drained Ground, Computers and Geotechnics, Vol. 12, No. 1, pp. 73-87, 1991.

[10] J.Q. Su, and Z. Wang, The Two-Dimensional Consolidation Theory of Electro-Osmosis", Technical Note, Geotechnique, Vol. 53, No. 8, pp. 759-763, 2003.

[11] X. Cao, and Z. Yin, Analysis of Two-Dimensional Consolidation of Unsaturated Soils, Characterization, Modeling, and Performance of Geo-materials, ASCE Library, pp. 33-39, 2009. 
[12] D. Turner, K. Nakshatrala, and M. Martinez, Frame Work for Coupling Flow and Deformation of A Porous Solid, International Journal of Geomechanics, ASCE, Vol. 15, No. 5, pp. 782-798, 2015.

[13] C.W. Cryer, A Comparison of the Three-Dimensional Consolidation Theories of Biot and Terzaghi, Oxford Journal of Mechanics and Applied Mathematics, Vol. 16, No. 4, pp. 401-412, 1993.

[14] S.M.V. Dark, D.G. Fredlund, and H. Rahardjo, Coupled ThreeDimensional Consolidation, Proceeding of Fifth International
Conference on Expansive Soils, Adelaide, Australia, pp. 99-103, 1984.

[15] Alnos, Analysis of Consolidation Equations of Compressed Clayey Soil, Journal of Environmental Science for Sustainable Society (JESSS), Japan,Vol.20, app 51-61,2015. 